\title{
Development of a Particle-Trap Preconcentration-Soft Ionization Mass Spectrometric Technique for the Quantification of Mercury Halides in Air
}

\author{
Daniel A. Deeds, Avik Ghoshdastidar, Farhad Raofie, Élise-AndreéGuérette, Alain Tessier, and Parisa A. Ariya
}

\begin{abstract}
Measurement of oxidized mercury, $\mathrm{Hg}(\mathrm{II})$, in the atmosphere poses a significant analytical challenge as $\mathrm{Hg}(\mathrm{II})$ is present at ultra-trace concentrations (picograms per cubic meter air). Current technologies are sufficiently sensitive to measure the total $\mathrm{Hg}$ present as $\mathrm{Hg}$ (II) but cannot determine the chemical speciation of $\mathrm{Hg}$ (II). We detail here the development of a soft ionization mass spectrometric technique coupled with preconcentration onto nano- or microparticle-based traps prior to analysis for the measurement of mercury halides in air. The current methodology has comparable detection limits $\left(4-11 \mathrm{pg} \mathrm{m}^{-3}\right)$ to previously developed techniques for the measurement of total inorganic mercury in air while allowing for the identification of $\mathrm{HgX}_{2}$ in collected samples. Both mercury chloride and mercury bromide have been sporadically detected in Montreal urban and indoor air using atmospheric pressure chemical ionization-mass spectrometry (APCI-MS). We discuss limitations and advantages of the current technique and discuss potential avenues for future research including quantitative trace measurements of a larger range of mercury compounds.
\end{abstract}

Mercury, a toxic heavy metal that bioaccumulates up aquatic food chains, ${ }^{1}$ is elevated above preindustrial levels in the environment due primarily to emissions associated with precious metals mining and coal-fired power plant production. ${ }^{2,3}$ The oxidation state ( 0 vs II) and phase of anthropogenic mercury (gaseous vs particle-bound) largely determines its removal rate from the atmosphere, ${ }^{4,5}$ with $\mathrm{Hg}(0)_{(\mathrm{g})}$ being relatively insoluble and inert compared to $\mathrm{Hg}(\mathrm{II})_{(\mathrm{g})}$ or particle-bound $\mathrm{Hg} .{ }^{4,5}$ Understanding the chemical makeup of anthropogenic mercury emissions and subsequent chemical transformations after release is a crucial step toward

assessing the balance between mercury deposition to nearby soils and waterways ${ }^{4-6}$ and transport to remote, pristine environments (e.g., the Arctic). ${ }^{7}$

Current atmospheric mercury measurements are mainly limited to the study of bulk mercury reservoirs: specifically, mercury is measured as gaseous elemental mercury (GEM, $\mathrm{Hg}^{0}$ ), as $\mathrm{Hg}^{0}$ derived from the chemical reduction or pyrolysis of gaseous oxidized mercury (GOM, or reactive gaseous community. Methods for the measurement of GOM are presented in Table S1, Supporting Information. ${ }^{8-14}$

Intercomparison of mercury speciation methods, including equivalent instrumentation, has shown large differences in measured mercury speciation, ${ }^{15}$ attributed to incomplete mercury capture and to wall losses or heterogeneous reactions in the sampling manifold. In addition, $\mathrm{KCl}$ denuder-cold vapor atomic fluorescence spectroscopy (CV-AFS), a technique often used to measure GOM, may preferentially collect certain types of $\mathrm{Hg}(\mathrm{II})^{14}$ and is susceptible to passivation by atmospheric oxidants and humidity at atmospherically relevant concentrations. ${ }^{16,17}$

Thermal decomposition to $\mathrm{Hg}^{0}$ allows for sensitive detection of total $\mathrm{GOM}$ or $\mathrm{Hg}_{(\mathrm{P})}$ but destroys their chemical identity. These measurements provide insight into the transfer of mercury between the atmosphere, waters, snow, and soils (e.g., refs $6,7,18-20$ ) but may not necessarily inform one about rates of deposition to, reemission from, and methylation in aquatic environments. ${ }^{1}$ The direct chemical speciation of mercury in the atmosphere would close crucial gaps in the geochemistry of mercury, providing better ability to assess the impact of mercury emissions on the environment. Gas chromatography-mass spectrometry has been used to directly identify mercuric nitrate and mercury chloride in simulated flue gases, but the concentrations involved $\left(\mu \mathrm{g} \mathrm{Hg} \mathrm{m}^{-3}\right)$ are significantly higher than the atmospheric GOM background. ${ }^{11}$ Recent method development has begun to address the chemical speciation of mercury 
through thermal decomposition profiles of captured $\mathrm{Hg},{ }^{15}$ but profiles produced are complicated by codesorption of contaminants.

Mercury halides $\left(\mathrm{HgX}_{2}, \mathrm{X}=\mathrm{Cl}, \mathrm{Br}, \mathrm{I}\right)$ are thought to be one of the principal forms of oxidized mercury in the atmosphere. ${ }^{4,5}$ In particular, $\mathrm{HgBr}_{2}$ is implicated in atmospheric mercury depletion events observed at the poles ${ }^{7}$ and midlatitudes. ${ }^{15}$ As of yet, mercury halides have not been directly observed in the atmosphere; their presence in air is instead inferred from correlations of GOM with atmospheric oxidants such as $\mathrm{BrO}$ and $\mathrm{Br} .{ }^{15}$ Other potential forms of $\mathrm{Hg}(\mathrm{II})$ are $\mathrm{HgO}, \mathrm{HgSO}_{4}, \mathrm{Hg}\left(\mathrm{NO}_{2}\right)_{2}$, and $\mathrm{Hg}(\mathrm{OH})_{2} \cdot{ }^{21-23}$

We report here an analytical methodology for the detection of mercury halides at atmospherically relevant concentrations $\left(10^{-12} \mathrm{~g} \mathrm{Hg} \mathrm{m}^{-3}\right.$ air) by nano- or micro-particle trapping coupled with atmospheric pressure chemical ionization-mass spectrometry (APCI-MS). We also present initial measurements of mercury halides in urban and indoor air. The limitations and potential future applications of the technique will be discussed.

\section{METHOD DEVELOPMENT}

This section details the tests taken to address the analytical challenge posed by the trace quantities of oxidized mercury present in the atmosphere. We discuss APCI optimization through selection of a CI gas for facile $\mathrm{HgX}_{2}$ identification (APCI Source Parameter Optimization) while minimizing side products and the selection of APCI ionization parameters to improve ion production and transmission into the MS. We then discuss development of particle-based sorbent traps (Sorbent Trap Packing) for $\mathrm{HgX}_{2}$ collection from ambient air $\left(\mathrm{HgX}_{2}\right.$ Breakthrough and Retention). We end by detailing initial tests of the complete APCI-MS system in urban and indoor air (Air Analyses, McGill University, Montreal Quebec, Canada).

Source Modification and CI Gas Selection. Gas phase $\mathrm{HgX}_{2}$ species were detected using an Agilent 6130 single quadrupole MS with APCI ion source installed. APCI-MS was chosen over electron ionization MS (EI-MS) as EI-MS fragments $\mathrm{HgX}_{2}$ into $\mathrm{Hg}^{+}$and $\mathrm{X}^{-}$ions (Figure S1a, Supporting Information) that are indistinguishable from those produced by elemental mercury or halogenated species in air extracts. EI-MS can produce small amounts of molecular ion for $\mathrm{Hg}(\mathrm{II})$ detection ${ }^{11}$ but only at high concentrations applicable to extreme atmospheric conditions (e.g., power plant flue gas).

In contrast, APCI is a "soft" ionization producing mainly molecular ions with less fragmentation than EI-MS due to indirect ionization via a solvent and due to minimal wall-losses and ion thermalization at the ambient pressures of the inlet (Figure S1b, Supporting Information). The APCI inlet of the Agilent 6130 nebulizes aqueous samples for gasphase analysis; we removed the inlet nebulizer and widened the inlet to accommodate a $6 \mathrm{~mm}$ gas-line or sorbent trap (Figure S2, Supporting Information). A programmable oven heats the inlet, such that wall losses of analytes are minimized or desorption of analytes can be performed.

Moving from aqueous- to gas-phase APCI analysis required thereplacement of the solvent with areagent gas. Ionization via charge transfer from nitrogen resulted in high residual energy on ionized $\mathrm{HgX}_{2}$, causing extensive ion fragmentation (Figure S3a,b, Supporting Information). A variety of CI reagent gases were tested for retention of incoming mercury species (Table 1). In almost all tests, the CI gas was supplied by placing a $3 \mathrm{~L}$

dual side-arm glass flask containing 1 atm of reagent gas in-line between a UHP nitrogen tank (at 80 psig, flowing at $1 \mathrm{~L}$ $\left.\min ^{-1}\right)$ and a $6 \mathrm{~L}$ dual side-arm glass flask containing $\mathrm{HgX}_{2}$ powder $(\sim 10 \mathrm{~g})$ under a nitrogen headspace. Nitrogen gas from the tank mixed sequentially with $\mathrm{CI}$ gas and $\mathrm{HgX}_{2}$-rich gas in the 3 and $6 \mathrm{~L}$ flasks, respectively, prior to entering the APCI ion source. One-hour tests showed no signal decrease from $\mathrm{HgX}_{2}$ standards, indicating a constant flux of mercury halide over this time period. Continuous scan-mode monitoring of masses in negative-ion mode $(175 \leq m / z \leq 550)$ allowed for detection of ions formed from incoming $\mathrm{HgX}_{2}$ as the reagent gas was diluted

with the nitrogen pushing gas. Qualitative results of CI gas tests are presented in Table 1. Several aqueous phase analyses are presented as well, including one for mercuric oxide. Aqueous mercuric oxide $(a t \mathrm{pH}=7)$ was detected as $\left[\mathrm{Hg}(\mathrm{OH})_{2}\right]^{+}$using positive-mode APCI. Early tests on CI gases were performed using a Waters Micromass Quattro tandem quadrupole LC-MS at the Center for Biological Applications of Mass Spectrometry (CBAMS) at Concordia University. The Quattro LC-MS inlet line for aqueous analytes was replaced by $6.3 \mathrm{~mm}$ PTFE tubing for direct 
connection to $\mathrm{HgX}_{2}$ standards.

Tests for the CI blend of isobutane (MEGS, >99.5\% purity) and sulfur hexafluoride (MEGS, >99.95\% purity) replaced the $3 \mathrm{~L}$ flask and nitrogen tank with pressurized tanks whose outflow were controlled via flowmeters to a total flow of 1 $\mathrm{L} \mathrm{min}^{-1}$ (at $10 \mathrm{psig}$ ). The standard used for these tests consisted of 5-mesh $\mathrm{HgX}_{2}$ pellets or powder packed into a $6 \mathrm{~mm}$ ID PFA tubing with dichlorodimethylsilane (DCDMS)-coated glass wool or Teflon septa (Figure S4, Supporting Information). We transitioned from the flask standard to packed standards as they were more compact, portable, and easier to manipulate in the laboratory. Packed standards were calibrated by repeat measurement of emitted $\mathrm{HgX}_{2}$ by $\mathrm{KCl}$ denuder coupled with CV/AFS. The $\mathrm{KCl}$ denuder was found to collect $90 \pm 6 \%(n=26)$ of incoming $\mathrm{Hg}$ (II) from standards based on CV/AFS analysis during sampling of standards vs during denuder heating at $500{ }^{\circ} \mathrm{C}$ (Figure S5, Supporting Information). $\mathrm{HgX}_{2}$ packed standards emitted $\mathrm{Hg}$ concentrations of $50 \pm 20 \mathrm{ng} \mathrm{Hg} \mathrm{L}^{-1}$.

Mercury halides preferentially undergo complexation with other constituents in the ion source (Table 1). Many of the ions observed can be attributed to atmospheric contaminants, such as $\left(\mathrm{H}_{2} \mathrm{O}\right)^{-}(\mathrm{m} / z=n \times 18)$ or $\mathrm{O}^{-}(\mathrm{m} / z=16)$. Masses of $m / z=19,35$, and 80 correspond to the halides $\mathrm{F}, \mathrm{Cl}$, and $\mathrm{Br}$. The APCI source for the Agilent single quadrupole MS was freer of contaminants than the Waters tandem quadrupole MS: the Agilent MS produced only $\left[\mathrm{HgCl}_{3}\right]^{-}$with $100 \% \mathrm{~N}_{2}$ (Figure S3a, Supporting Information). The presence of $\mathrm{HgX}_{3}{ }^{-}$ions suggests that fragmentation occurred, although it was mainly limited to when the reagent gas recombination energy (equivalent in magnitude to its ionization potential) was greater than the analyte's ionization energy. In this case, the residual energy left after charge transfer resulted in ion fragmentation.

Of the CI gases studied, we initially selected isobutane (IB) as it produced simple spectra consisting of an ion complex $\left([\mathrm{M}+26]^{-}\right)$of the analyte and an isobutane fragment $\left(\mathrm{m} / \mathrm{z}=26\right.$, speculated to be $\left.\mathrm{C}_{2} \mathrm{H}_{2}\right)$ and small peaks corresponding to the molecular ion and to trihalide ions (e.g., $\left[\mathrm{HgCl}_{3}\right]^{-},\left[\mathrm{HgBr}_{2} \mathrm{Cl}\right]^{-}$). Isobutane and UHP nitrogen were blended in proportions of $0-100 \% \mathrm{IB} / \mathrm{N}_{2}$ using flowmeters (total flow of $1 \mathrm{~L} \mathrm{~min}^{-1}$ at $10 \mathrm{psig}$ ) connected by a PFA tee to a single $\mathrm{HgX}_{2}$ packed standard connected directly to the APCI inlet. A blend

of 10:90 IB/ $\mathrm{N}_{2}$ was selected as a compromise between high sensitivity detection of both $\mathrm{HgCl}_{2}$ and $\mathrm{HgBr}_{2}$ and economizing reagent gases (Figure S6, Supporting Information). We note that direct chemical identification of $\mathrm{Hg}(\mathrm{II})$ via $[\mathrm{M}]^{-}$was possible using $100 \% \mathrm{IB}$ as a $\mathrm{CI}$ gas, but the relative yield of $[\mathrm{M}]^{-}$in selected ion monitoring (SIM) mode (e.g., $1.2 \times 10^{4} \mathrm{cts}$ ) was an order of magnitude less than the yield of [M+26] $]^{-}$for the same standard with a 10:90 IB/ $\mathrm{N}_{2} \mathrm{CI}$ gas (e.g., $2.2 \times 10^{5} \mathrm{cts}$ in SIM mode).

To test for analyte loss to in-source reactions, we introduced both $\mathrm{HgCl}_{2}$ and $\mathrm{HgBr}_{2}$ into the APCI ion source from a 50:50 (by mass) $\mathrm{HgCl}_{2} / \mathrm{HgBr}_{2}$ standard consisting of 5-mesh $\mathrm{HgX}_{2}$ particles in a $6 \mathrm{~mm}$ ID PFA tube packed between Teflon septa. The mixed standard source was placed upstream of a shredded Teflon sorbent trap (discussed below in Sorbent Trap Desorption: Timing and Temperature and Sorbent Trap Packing), blanked at $200{ }^{\circ} \mathrm{C}$ in the APCI inlet, and connected to a field pump. $\mathrm{HgX}_{2}$ was collected onto the trap for $1 \mathrm{~min}$ at $1 \mathrm{~L} \mathrm{~min}^{-1}$ prior to desorption into the APCI source at $200{ }^{\circ} \mathrm{C}$ with a 10:90 IB/ $\mathrm{N}_{2} \mathrm{CI}$ gas flowing through the trap at $1 \mathrm{~L} \mathrm{~min}^{-1}$. $\mathrm{HgCl}_{2}$ and $\mathrm{HgBr}_{2}$ sequentially desorb from the trap into the APCI source (Figure S7, Supporting Information). The

major ion observed during APCI-MS analysis of the mixed halide was $\mathrm{m} / z=343$, corresponding to $[\mathrm{HgBrCl}+26]^{-}$. $\mathrm{HgBrCl}$ was detected only after both $\mathrm{HgX}_{2}$ compounds are present in the APCI inlet suggesting that $\mathrm{HgBrCl}$ was an artifact of ion reactions rather than being a desorbed analyte. Currently, $\mathrm{HgBrCl}$ cannot be considered a legitimate environ- mental signal if detected in air extracts.

In an attempt to limit ion reactions in the APCI inlet, we analyzed the $\mathrm{HgCl} / \mathrm{HgBr}$ standard using a sulfur hexa uoride/IB blend as a CI gas. Sulfur hexafluoride $\left(\mathrm{SF}_{6}\right)$, a strong electron acceptor, ${ }^{24}$ decomposed into $\mathrm{SF}_{5}{ }^{+}+\mathrm{F}^{-}$in the APCI ion source (Figure S8, Supporting Information). Fluoride ion complexed with $\mathrm{HgX}_{2}$ to produce $\mathrm{m} / z=291$ ( $\left[\mathrm{HgCl}_{2} \mathrm{~F}\right] ; 40 \%$ relative abundance), $m / z=336\left([\mathrm{HgBrClF}]^{-} ; 100 \%\right.$ relative abundance), and $\mathrm{m} / \mathrm{z}=381\left(\left[\mathrm{HgBr}_{2} \mathrm{~F}\right]^{-}\right.$; $80 \%$ relative abundance). Although the $\mathrm{SF}_{6} / \mathrm{IB}$ CI gas does not prevent in-source ion reactions, it provides a complementary analysis yielding alternate ions that may aid in positive identification of $\mathrm{HgX}_{2}$ where contaminants are present at $\mathrm{m} / \mathrm{z}$ of $[\mathrm{M}+26]^{-}$.

Target ion abundances in scan-mode spectra with $\mathrm{CI}$ by IB/ $\mathrm{N}_{2}$ and SF6/IB were comparable, with principal ion abundances on the order of $(2-3) \times 10^{4}$ cts. The yields of $[\mathrm{M}+\mathrm{F}]^{-}$for blends of 0.5:99.5 to 99.5:0.5 $\mathrm{SF}_{6} / \mathrm{IB}$ were relatively constant suggesting that $\mathrm{HgX}_{2}$ supplies a limited ion complex formation rather than $\mathrm{F}^{-}$production. To conserve $\mathrm{SF}_{6}$, a $0.5 \% \mathrm{SF}_{6}$ in $\mathrm{IB}$ blend was used for all subsequent $\mathrm{SF}_{6} / \mathrm{IB}$ tests. 
Sorbent Trap Desorption: Timing and Temperature. Direct insertion of $\mathrm{HgX}_{2}$ standards into the APCI inlet led to persistentblanks (e.gFigure S3b, Supporting Information) and signal degradation over time. To introduce controlled, smaller quantities of analyte, we collected $\mathrm{HgX}_{2}$ onto homemade sorbent traps consisting of $6 \mathrm{~mm}$ ID glass tubing packed with copper-doped iron nanoparticles silanized with bis[3-(triethox- ysilyl) propoyl] tetrasulfide ${ }^{25}$ electrostatically held on $5 \mu \mathrm{m}$ glass beads or with shredded PFA tubing, held in place with glass wool and stainlesssteel wire (Figure S9, Supporting Information). Standards were connected with PFA connectors upstream of a sorbent trap attached to a field pump, with flow

controlled to $1 \mathrm{~L} \mathrm{~min}^{-1}$ by an acrylic flowmeter downstream of the trap (Figure S10, Supporting Information). After pumping,

a sorbent trap was immediately connected to a gas line teed to CI gases via a blanked PFA elbow and inserted into the APCI inlet. Initial tests indicated an optimal desorption temperature of $200{ }^{\circ} \mathrm{C}$, with $\mathrm{CI}$ gas flow starting at $0.2 \mathrm{~min}$ after insertion (Figure S11, Supporting Information). A decreased signal at $225^{\circ} \mathrm{C}$ may result from thermal decomposition of $\mathrm{HgX}_{2}{ }^{26} \mathrm{~A}$ desorption of $1.2 \mathrm{~min}$ was sufficient to release captured analyte into the APCIinlet. Unless stated otherwise, the following tests involve $\mathrm{HgX}_{2}$ collection over 1 min followed by desorption into the APCI inlet as described in this section.

APCISourceParameter Optimization. Ion production in the APCI source is controlled through manipulation of three main parameters: the current through the corona discharge pin, the voltage applied across the capillary between the APCI source and MS, and the voltage excess applied to the fragmentor, a charged section between the capillary and MS that accelerates ions for controlled fragmentation. These parameters control coronal intensity, in-source fragmentation, and ion complexation (corona current), as well as ion transmission to the MS (capillary and fragmentor voltage).

APCI analyses of $\mathrm{HgCl}_{2}$ and/or $\mathrm{HgBr}_{2}$ collected on polysulfide traps for $1 \mathrm{~min}$ at $1 \mathrm{~L} \mathrm{~min}^{-1}$ (Sorbent Trap Desorption: Timing and Temperature) using the IB/ $\mathrm{N}_{2}$ CI gas were taken at corona currents of 10, 20, 30, and $40 \mu \mathrm{A}$. For each step in corona current, triplicate measurements using capillary voltages of 500, 1500, 3000 , and $4000 \mathrm{~V}$ were taken. For each capillary voltage, the fragmentor voltage was set to 20,40 , and $60 \mathrm{~V}$ above the capillary voltage. Inlet and drying gas temperatures were set to $200{ }^{\circ} \mathrm{C}$ with a drying gas flow rate of $3 \mathrm{~L} \mathrm{~min}^{-1}$. $\mathrm{HgX}_{2}$ detected in SIM mode for $m / z$ of $294-301\left(\mathrm{HgCl}_{2}\right)$ and 382- $391\left(\mathrm{HgBr}_{2}\right)$, with the principal signal for the compounds taken as the height of $\mathrm{m} / \mathrm{z}=298$ and 388, respectively.

$\mathrm{HgCl}_{2}$ and $\mathrm{HgBr}_{2}$ ion production and transmission using $\mathrm{SF}_{6} / \mathrm{IB}$ were also tested for 1 min extracts of air passing through the mixed $\mathrm{HgX}_{2}$ standard onto a shredded Teflon trap, at capillary voltages of 500, 750, 1500, 2500, and $4000 \mathrm{~V}(30 \mu \mathrm{A}$ corona current) and at corona currents of $1,5,10,20,30$, and $40 \mu \mathrm{A}(750 \mathrm{~V}$ capillary voltage). Drying gas and inlet temperatures were set to $200{ }^{\circ} \mathrm{C}$ with a drying gas flow rate of $5 \mathrm{~L}$ min- 1 , and the fragmentor excess voltage was set to $60 \mathrm{~V}$. A series of tests at fragmentor voltages of 20, 40, 60, 80, 100, 120, and 140 V was also performed with similar inlet temperature/ flow conditions and a corona current of $30 \mu \mathrm{A}$ and capillary voltage of $750 \mathrm{~V} . \mathrm{HgX}_{2}$ was detected in SIM mode for $\mathrm{m} / \mathrm{z}$ of $290-295\left(\mathrm{HgCl}_{2}\right)$ and $378-383\left(\mathrm{HgBr}_{2}\right)$, with the principal signal for the compounds taken as the height of $\mathrm{m} / \mathrm{z}=291$ and 381 , respectively.

Sorbent Trap Packing. In addition to polysulfide and shredded Teflon traps, we also tested the performance of magnetite, silver pellet, cobalt chloride, and glass wool traps for collection of $\mathrm{HgX}_{2}$. Construction of these traps was as described in Sorbent Trap Desorption: Timing and Temper-ature. A full-Teflon trap consisting of shredded Teflon packed into a $6 \mathrm{~mm}$ PFA tube was also tested. $\mathrm{HgX}_{2}$ was collected from air pumped through the $\mathrm{HgCl}_{2} \mathrm{particle} \mathrm{or}$ mixed mercuryhalide standard for typically $1 \mathrm{~min}$ at $1 \mathrm{~L} \mathrm{~min}^{-1}$, followed by desorption into the APCI source at 150-200 ${ }^{\circ} \mathrm{C}$. APCI source parameters were set to the optimums described below in APCI

Parameter Optimization, using the $\mathrm{SF}_{6} / \mathrm{IB}$ CI blend. $\mathrm{HgX}_{2}$ was detected in SIM mode for $m / z$ of $290-295\left(\mathrm{HgCl}_{2}\right)$ and $378-383\left(\mathrm{HgBr}_{2}\right)$, with the principal signal for the compounds taken as the height of $m / z=291$ and 381, respectively. Results can be found in Table S2, Supporting Information.

$\mathrm{HgX}_{2}$ Breakthrough and Retention. Initial $\mathrm{HgX}_{2}$ break- through testing involved two polysulfide traps connected in series with a $\mathrm{HgCl}_{2}$ source, flowing air through the standard onto the traps at $1 \mathrm{~L} \mathrm{~min}^{-1}$ for varying exposure times (5 s-14 min). After exposure, traps were removed and inserted into the APCI inlet for IB/ $\mathrm{N}_{2}$ analysis. The order of traps was noted; the proportion of total $\mathrm{HgX}_{2}$ collected on each trap gave a measure of trap breakthrough. The order 
of traps was changed between runs to prevent possible order bias on the results. A total of 17 runs was collected.

For Teflon traps, we compared the $\mathrm{Hg}$ mass collected on a $\mathrm{KCl}$ denuder from direct exposure to a mixed $\mathrm{HgX}_{2}$ standard to the mass of $\mathrm{Hg}$ collected with a shredded Teflon trap connected in-line between the denuder and the same $\mathrm{HgX}_{2}$ standard under identical conditions. Flow through the standard to the denuder was $1 \mathrm{~L} \mathrm{~min}^{-1}$ for $10 \mathrm{~s}$. After sampling, the denuder was placed in-line with the CV/AFS and heated to $500{ }^{\circ} \mathrm{C}$ to decompose trapped $\mathrm{Hg}$ (II) for CV/AFS analysis. Meanwhile, the Teflon trap, if used, was capped with paraffin film until analysis. After the denuder analysis, the Teflon trap was placed back in-line with the denuder (at room temperature), wrapped in heating tape, connected to a UHP nitrogen source, and heated to $200{ }^{\circ} \mathrm{C}$ for 1 min under a $\mathrm{N}_{2}$ flow of $1 \mathrm{~L} \mathrm{~min}^{-1}$ to transfer collected $\mathrm{HgX}_{2}$ onto the denuder. The denuder was then reconnected to the CV/AFS for heating and $\mathrm{Hg}$ analysis. The elevated concentrations emitted by our standards $\left(\mu \mathrm{g} \mathrm{Hg} \mathrm{m}^{-3}\right)$ preclude testing of long-term retention of $\mathrm{Hg}$ (II) on our sorbent traps. To assess $\mathrm{HgX}_{2}$ retention, we began by collecting $\mathrm{HgX}_{2}$ onto the Teflon trap as described above. The $\mathrm{HgX}_{2}$-containing trap was then connected to the UHP $\mathrm{N}_{2}$ line and left under a flow of $1 \mathrm{~L}$ $\min ^{-1} \mathrm{~N}_{2}$ for $24 \mathrm{~h}$. At the end of $24 \mathrm{~h}$, the trap was connected back in-line with the $\mathrm{KCl}$ denuder, wrapped in heating tape, and heated to $200{ }^{\circ} \mathrm{C}$ for 1 min under a $\mathrm{N}_{2}$ flow of $1 \mathrm{~L} \mathrm{~min}^{-1}$ to transfer retained $\mathrm{HgX}_{2}$ onto the denuder for decomposition to $\mathrm{Hg}^{0}$ and CV/AFS analysis.

Air Analyses, McGill University, Montreal Quebec, Canada. Air samples were collected during Fall 2013 and Winter 2014 from the roof of Burnside Hall ( 60 m height) on the McGill campus for same-day analysis by APCI-MS $\left(\mathrm{SF}_{6} / \mathrm{IB}\right.$ method). Typically, two of the traps were a polysufide and a shred Teflon trap, with a third trap for alternate trap compositions. Air sampling for all traps was 1 day in length (4 PM to 4 PM).

Traps were blanked in the APCI inlet at $200^{\circ} \mathrm{C}$ before being plumbed via PFA connectors and tubing to rotometers connected in parallel to a field pump. Trap inlets were exposed directly to the air. Traps were wrapped in heating tape at $50{ }^{\circ} \mathrm{C}$ to inhibit water condensation. At the end of sampling, traps were removed from the manifold, sealed with paraffin film, placed in new plastic bags, and transported into the laboratory for analysis. Time between the end of sampling and analysis was typically 15-30 min. Traps were analyzed as described in Sorbent Trap Desorption: Timing and Temperature.

To test whether $\mathrm{HgCl}_{2}$ may be produced by chlorine emitted by swimming pools, we installed the air sampling equipment on the deck of the Memorial Pool at McGill University from January to March 2014. Samples were collected for $12 \mathrm{~h}$ overnight (10 PM to $10 \mathrm{AM}$ ). Sampling setup and analysis was identical to the setup installed on Burnside Hall.

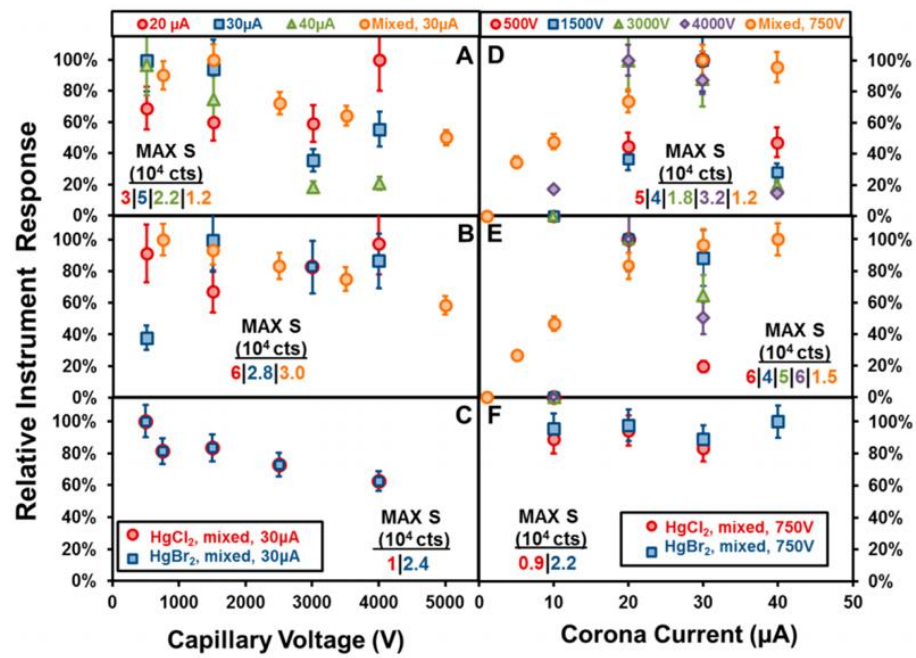

Figure 1. Comparison of the APCI-MS response with varying capillary voltage (left-hand side plots) or corona current (right-hand side plots) for $\left[\mathrm{HgCl}_{2}+26\right]^{-}(\mathrm{A}, \mathrm{D})$ and $\left[\mathrm{HgBr}_{2}+26\right]^{-}(\mathrm{B}, \mathrm{E})$ using a $10: 90 \mathrm{IB} / \mathrm{N}_{2} \mathrm{CI}$ gas blend and for both compounds $\left(\mathrm{as}[\mathrm{M}+19]^{-}\right)$using a SF 6 / IB CI blend (C, F). Most tests used single $\mathrm{HgX}_{2}$ standards with the exception of those marked "mixed" which used the $50: 50 \mathrm{HgCl}_{2} / \mathrm{HgBr}_{2}$ mixed standard (described in Source Modification and CI Gas Selection). Values are relative responses (\% of maximum signal) segregated by corona current (in $\mu \mathrm{A}$, for capillary voltage tests) or by capillary voltage (corona current tests) and are the mean of 3-6 measurements, with standard deviations of around $\pm 30 \%$ 


\section{RESULTS AND DISCUSSION}

APCI Parameter Optimization. Figure 1 displays $\mathrm{HgX}_{2}$ ion complex production at varying capillary voltage and corona current for IB/ $\mathrm{N}_{2}$ or $\mathrm{SF}_{6} / \mathrm{IB}$ CI gases. Broad patterns are evident, and optimal conditions for APCI analysis of $\mathrm{HgX}_{2}$ are discussed below.

The response of the APCI-MS to $\mathrm{HgCl}_{2}$ generally decreased with increasing capillary voltage (Figure 1a,c). $\mathrm{The}_{\mathrm{HgBr}}$ signal was relatively constant with increasing capillary voltage for the single standard but decreased for the mixed standard (Figure 1b,c). The discrepancy may arise from comparison of the more variable flux coming off fine powder single-compound standards versus the large-particle mixed $\mathrm{HgX}_{2}$ standard. The relative decrease in $\left[\mathrm{HgX}_{2}+19\right]$ with increasing capillary voltage was similar for both $\mathrm{HgBr}_{2}$ and $\mathrm{HgCl}_{2}$ using either $\mathrm{CI}$ gas. Capillary voltages in the range of 750-1500 V are optimal for APCI analysis of $\mathrm{HgX}_{2}$.

In this study, corona current optimization balances CI gas fragmentation with ion complex preservation. The effect of these competing phenomena is illustrated in the peak $\mathrm{HgX}_{2}$ signal for corona currents of 20-30 $\mu \mathrm{A}$ (Figure 1d-f). When using 10:90 IB/ $\mathrm{N}_{2}$ as a CI gas, lower corona currents $(<20 \mu \mathrm{A})$ resulted in little to no $[\mathrm{M}+26]^{-}$formation, presumably due to limited isobutane fragmentation. At high corona current, the $[\mathrm{M}+26]^{-}$yield either decreased or remained constant, suggesting that analyte was lost to fragmentation and/or

complexation with an ionized contaminant. For APCI using $\mathrm{SF}_{6} / \mathrm{IB}$, the yield of $[\mathrm{M}+19]^{-}$was relatively constant with varying corona current. At a capillary voltage of $750-1500 \mathrm{~V}$, the optimal corona current for APCI analysis of $\mathrm{HgX}_{2}$ is $30 \mu \mathrm{A}$.

The fate of $\mathrm{HgX}_{2}$ with nonoptimal corona currents varied depending on which $\mathrm{HgX}_{2}$ standard was used; scans $(200 \leq$ $m / z \leq 500$ ) of single $\mathrm{HgX}_{2}$ standards with the $\mathrm{IB} / \mathrm{N}_{2}$ CI blend showed the predominant complex formed at low and high corona current was $\left[\mathrm{HgX}_{3}\right]^{-}$. $\mathrm{HgBr}_{2}$ from the single standard runs was converted into $\left[\mathrm{HgBr}_{2} \mathrm{Cl}\right]^{-}, \operatorname{not}\left[\mathrm{HgBr}_{3}\right]^{-}$, in the ion source, suggesting that chloride contamination was not solely from analyte fragmentation. The sorbent traps used for single $\mathrm{HgBr}_{2}$ tests contained DCDMS-coated glass wool packing; it is probable that at inlet temperatures of $200{ }^{\circ} \mathrm{C}$ chlorine- containing gases were emitted from the glass wool into the source. Tests using the mixed $\mathrm{HgX}_{2}$ standard involved direct introduction of an analyte-rich gas stream without preconcentration. Scans of the mixed $\mathrm{HgX}_{2}$ standard predominantly showed $[\mathrm{M}+32]^{-}$at corona currents $<20 \mu \mathrm{A}$ and $[\mathrm{M}+16],[\mathrm{M}+17]$, and [M+32]at a corona current of $40 \mu \mathrm{A}$, consistent with complexation with atomic oxygen $\left(\mathrm{O}^{-}, \mathrm{m} / \mathrm{z}=16\right)$, hydroxide $\left(\mathrm{OH}^{-}\right.$, $\mathrm{m} / \mathrm{z}=17)$, and molecular oxygen $(\mathrm{O} 2-, \mathrm{m} / \mathrm{z}=32)$ formed from molecular oxygen and water in the ion source.

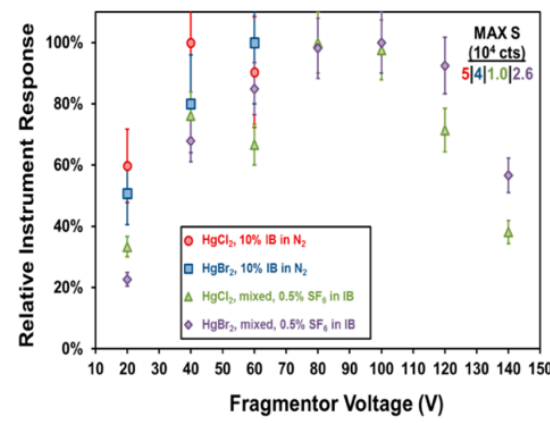

Figure 2. Comparison of the APCI-MS response with varying fragmentor voltage for $\mathrm{HgCl}_{2}$ and $\mathrm{HgBr}_{2}$ using either a $\mathrm{IB} / \mathrm{N}_{2}$ or $\mathrm{SF}_{6} / \mathrm{IB}$ CI blend. IB/ $/ \mathrm{N}_{2}$ tests used single $\mathrm{HgX}_{2}$ standards while $\mathrm{SF}_{6} / \mathrm{IB}$ runs used the $50: 50 \mathrm{HgCl}_{2} / \mathrm{HgBr}_{2}$ mixed standard (described in Source Modification and CI Gas Selection). Values are relative responses (\% of maximum signal) and are the mean of 3 measurements, with standard deviations of around $\pm 10-30 \%$. 
Figure 2 shows the APCI response to $\mathrm{HgX} 2$ for varying fragmentor voltage. Initial tests using the IB/N2 CI blend at voltages of 20-60 V suggested that ion transmission was relatively constant for voltages $>20 \mathrm{~V}$ (Figure 2 ). Later, tests using SF6/IB at voltages of 20-140 V indicate the highest ion transmission between 80 and $100 \mathrm{~V}$ (Figure 2). We therefore selected a fragmentor voltage of $80 \mathrm{~V}$ as optimal for $\mathrm{HgX}_{2}$ measurement.

Figure S12, Supporting Information, plots the APCI response to $\mathrm{HgX}_{2}$ with varying drying gas temperature and flow rate. In routine APCI-MS, the drying gas evaporates solvent, facilitating charge transfer to the solute, and acts as a screening gas to prevent neutral molecule transmission into the MS. Additionally, the drying gas temperature must be sufficiently elevated to prevent $\mathrm{HgX}_{2}$ adsorption to the capillary inlet. These conditions were met by increasing drying gas flow rate and temperature to $5 \mathrm{~L} \mathrm{~min}^{-1}$ at $200{ }^{\circ} \mathrm{C}$ (Figure $\mathrm{S} 12$,

Supporting Information). Increasing the flow rate past $5 \mathrm{~L} \mathrm{~min}^{-1}$ might decrease instrument sensitivity to $\mathrm{HgX}_{2}$, due to increased $\mathrm{N}_{2}$ concentrations in-source or to lower $\mathrm{HgX}_{2}$ residence times in the APCI inlet.

$\mathrm{HgX}_{2}$ Breakthrough and Retention. For exposure times of $\leq 7.5 \mathrm{~min}, \mathrm{HgCl}_{2}$ was observed only on the first trap in retention tests for polysulfide traps. At exposure times of $10-14 \mathrm{~min}, 4-25 \%$ of total $\mathrm{HgCl}_{2} \mathrm{Was}$ collected on the second trap in the series (average of $15 \pm 9 \%, n=4$ ).

The results of $\mathrm{HgX}_{2}$ breakthrough and retention tests for Teflon traps can be found in Figure S13, Supporting Information. Average $\mathrm{HgX}_{2}$ breakthrough through Teflon traps was $28 \pm 15 \%(n=3)$. The population mean of $\mathrm{HgX}_{2}$ collected on a Teflon trap desorbed immediately after loading into the $\mathrm{KCl}$ denuder versus after a $24 \mathrm{~h}$ pumping of $\mathrm{N}_{2}$ through the trap at $1 \mathrm{~L} \mathrm{~min}^{-1}$ was not significantly different $(n=3, p=0.21)$.

Calibration, Detection Limit Estimation, and Uncertainty. Figure S14, Supporting Information, shows representative calibration curves for APCI analysis of $\mathrm{HgX} 2$ standards using either polysulfide preconcentration and the IB/N2 CI gas ("PS:IB") or Teflon preconcentration and the SF6/IB CI gas ("PFA/SF6"). Instrument responses presented in Figure S14, Supporting Information, are the peak height of target masses for $\mathrm{HgCl} 2$ and $\mathrm{HgBr} 2$. The absolute mass of $\mathrm{HgX} 2$ collected on a sorbent trap was estimated from the collection time, and the $\mathrm{HgX} 2$ emission rate from the standard (pg HgX2 min-1) was estimated from a concentration of $50 \pm 20 \mathrm{ng} \mathrm{Hg}$ $\mathrm{L}-1$ and a flow rate of $1 \mathrm{~L}$ min -1 . Masses were increased by $28 \%$ for Teflon traps and were not adjusted for polysulfide traps, as exposure times were $<10 \min \left(\mathrm{HgX}_{2}\right.$ Breakthrough and Retention).

Practical equipment constraints prevented trapping of less than $40 \pm 10 \mathrm{pg} \mathrm{HgCl}_{2}$ and $50 \pm 10 \mathrm{pg} \mathrm{HgBr}_{2}$. To estimate detection limits, we extrapolated from the range covered by calibration curves down to $3 \sigma$ of the background noise. Detection limits are estimated to be $14 \mathrm{pg} \mathrm{HgCl}_{2}$ and $40 \mathrm{pg} \mathrm{HgBr}_{2}$ for the PS/IB method and $6 \mathrm{pg} \mathrm{HgCl}_{2}$ and $17 \mathrm{pg}$ $\mathrm{HgBr}_{2}$ for the $\mathrm{PFA} / \mathrm{SF}_{6}$ method. Quantities between detection limits and the lowest quantities directly measured are semi- quantitative but mainly cover the range below the limit of quantitation. For a sampling period of 1 day at 1 $\mathrm{L} \mathrm{min}^{-1}$, the detection limits presented correspond to concentration-based detection limits of $10 \mathrm{pg} \mathrm{HgCl}_{2} \mathrm{~m}^{-3}$ and 28 pg $\mathrm{HgBr}_{2} \mathrm{~m}^{-3}$ by PS/IB and $4 \mathrm{pg} \mathrm{HgCl}_{2} \mathrm{~m}^{-3}$ and $11 \mathrm{pg} \mathrm{HgBr}_{2} \mathrm{~m}^{-3}$ by PFA/SF 6 .

The sensitivity of the PFA/SF 6 technique was $1.4 \times 10^{2}$ cts pg ${ }^{-1} \mathrm{HgCl}_{2}$ and $5 \times 10^{1}$ counts pg $^{-1} \mathrm{HgBr}_{2}$, higher than

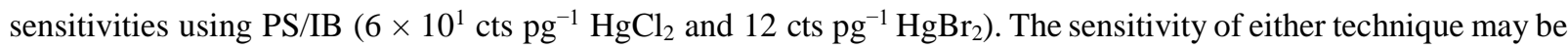
lower than that estimated from single $\mathrm{HgX}_{2}$ standards due to ion reactions in the APCI source. Concentrations determined using these calibration curves should be considered lower limits to atmospheric $\mathrm{HgX}_{2}$ concentrations during sampling.

The results presented in Figures 1 and 2 suggest that the reproducibility of $\mathrm{HgX}_{2}$ preconcentration and APCI analysis is $\pm 30 \%$. Estimates of $\mathrm{HgX}_{2}$ concentration $\left(\mathrm{pg} \mathrm{m}^{-3}\right)$ include uncertainty from calibration $( \pm 40 \%)$ and volume sampled $( \pm 10 \%$, based on flowmeter variability). Propagating relative errors gives an uncertainty of measurement of $\pm 50 \%$. 


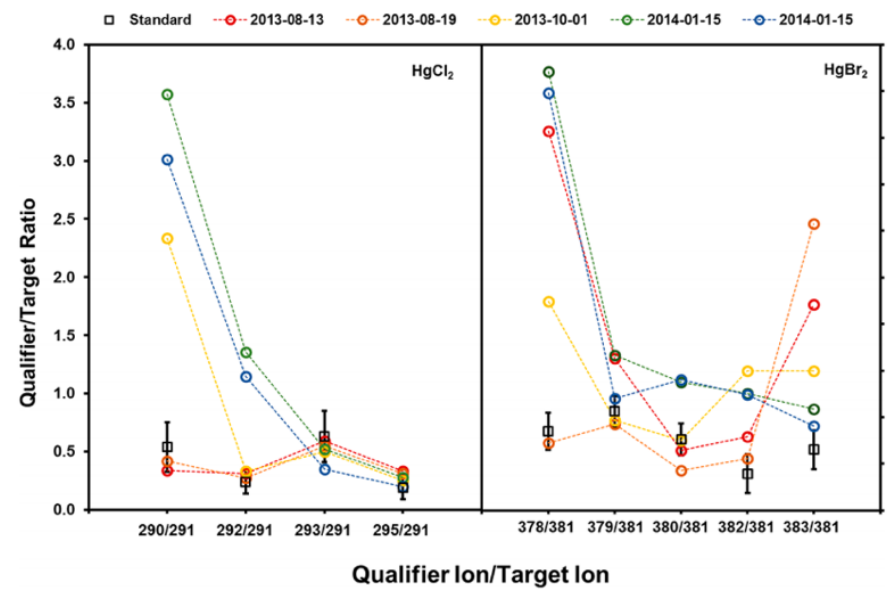

Figure 3. Qualifier/target $(\mathrm{Q} / \mathrm{T})$ ion ratios for SIM mode analyses of $\mathrm{HgCl}_{2}$ and $\mathrm{HgBr}_{2}$ in Montreal urban air from August 2013 to January 2014. $\mathrm{HgX}_{2}$ standard $\mathrm{Q} / \mathrm{T}$ ratios are shown in black with whiskers equal to 2 times their standard deviation. Sample $\mathrm{Q} / \mathrm{T}$ ratios falling within the range indicated by whiskers indicate a positive match with standard $\mathrm{Q} / \mathrm{T}$ ratios.

Air Measurements. APCI analyses of urban and pool air extracts collected on Teflon traps can be found in Figures 3 and S15 and Table S4, Supporting Information. Target ions were $m / z=291\left(\mathrm{HgCl}_{2}\right)$ and $m / z=381\left(\mathrm{HgBr}_{2}\right)$. Qualifier ions for $\mathrm{HgCl}_{2}$ were $\mathrm{m} / z=290,292,293$, and 295 and for $\mathrm{HgBr}_{2}$ were

$m / z=378,379,380,382$, and 383. Positive identification of $\mathrm{HgX}_{2}$ was made by comparing sample and standard qualifier- target $(\mathrm{Q} / \mathrm{T})$ ion ratios (i.e., the ratio of a qualifier ion signal to the target ion signal). Comparison was considered "excellent" if all sample $\mathrm{Q} / \mathrm{T}$ ratios were within $2 \sigma$ of standard $\mathrm{Q} / \mathrm{T}$ ratios, "good" if $3 \mathrm{Q} / \mathrm{T}$ ratios matched, "acceptable" if $2 \mathrm{Q} / \mathrm{T}$ ratios were consistent, and "poor" if $<2 \mathrm{Q} / \mathrm{T}$ ratios matched standard ratios. Representative SIM mode APCI analyses (PFA/SF 6 method) for samples collected at Memorial Pool and Burnside Hall, including trap blanks, are shown in Figure S16, Supporting Information. Trap blanks are significantly smaller than air measurements indicating that compounds detected are not analyte carryover.

$\mathrm{HgCl}_{2}$ detection was excellent in August 2013, good in October 2013, and acceptable in January 2014. $\mathrm{HgBr}_{2}$ detection was acceptable during August and October 2013 and possibly during January 2014, but identification was complicated by highly variable $\mathrm{Q} / \mathrm{T}$ ratios. $\mathrm{HgCl}_{2}$ detection in pool air was good throughout the sampling campaign, with $\mathrm{HgBr}_{2}$ only detected at an "acceptable" level once during the period. $\mathrm{Hg}^{0}$ injections through polysulfide and Teflon traps are statistically indistinguishable from direct $\mathrm{Hg}^{0}$ injections to the CV/AFS (Figure S17, Supporting Information) suggesting that $\mathrm{HgX}_{2}$ observed does not result from collection of $\mathrm{Hg}^{0}$ followed by heterogeneous oxidation to $\mathrm{Hg}(\mathrm{II}) . \mathrm{HgX}$ concentrations for

analytes collected onto shredded Teflon traps ranged from $<4$ to $1 \times 10^{2} \mathrm{pg} \mathrm{HgCl}_{2} \mathrm{~m}^{-3}$ and $<11$ to $9 \times 10^{1} \mathrm{pg}_{\mathrm{HgBr}}$ $\mathrm{m}^{-3}$ in Montreal urban air and (4-8) $\times 10^{1} \mathrm{pg} \mathrm{HgCl}_{2} \mathrm{~m}^{-3}$ and $<11$ to $29 \mathrm{pg} \mathrm{HgBr}_{2} \mathrm{~m}^{-3}$ in pool air. A fault in the APCI inlet oven lead to incomplete desorption during pool sample analyses, and

presented concentrations are lower limits.

\section{CONCLUSIONS AND FUTURE RESEARCH}

In this study, we provide the first chemical identification of atmospheric $\mathrm{Hg}(\mathrm{II})_{\mathrm{g})}$ using a novel nano/microparticle extraction-APCI-MS technique. Both $\mathrm{HgCl}_{2}$ and $\mathrm{HgBr}_{2}$ were detected in air extracts. Being trap-based, the technique is portable and shows promise as a valuable tool for studying mercury cycling in the environment. The technique could be extended to other forms of $\mathrm{Hg}(\mathrm{II})$ that may be present in the atmosphere, such as $\mathrm{HgO}$ or $\mathrm{HgI}_{2}$. Although in passing, we have shown that aqueous $\mathrm{Hg}$ (II) APCI analysis is feasible. Aqueous analysis using a softer ionization technique (electro- spray ionization) may be a valuable avenue of research for a wider range of oxidized mercury in different environmental and nonenvironmental matrices. Optimized APCI-MS analysis of $\mathrm{HgX}_{2}$ occurs at a 
corona current of $30 \mu \mathrm{A}$, capillary voltage of 750-1500 V, fragmentor voltage of $80 \mathrm{~V}$, and a drying gas temperature and flow rate of $200{ }^{\circ} \mathrm{C}$ and $5 \mathrm{~L} \mathrm{~min}^{-1}$.

The main weakness of this technique is the frequent presence of coadsorbed contaminants and decreased sensitivity to $\mathrm{HgX}_{2}$ from unwanted ion reactions in the APCI source. It would be advantageous to develop gas chromatographic separation of collected air samples, although GC separation may be limited by loss of $\mathrm{Hg}$ (II) to the column. ${ }^{11}$ The current sampling time of $24 \mathrm{~h}$ is long and needs to be reduced to bring the temporal resolution of $\mathrm{Hg}(\mathrm{II})$ measurements into parity with the much faster GEM and $\mathrm{Hg}_{(\mathrm{P})}$ techniques typically used. We foresee that in near future various combination of mass spectrometry techniques (e.g., MS/MS or MS/MS/MS or high resolution units), will further improve identification and quantification of a wider range of mercury species at trace levels.

\section{ASSOCIATED CONTENT}

Supporting Information

Additional information as noted in text. This material is available free of charge via the Internet at http://pubs.acs.org.

\section{AUTHOR INFORMATION}

\section{Corresponding Author}

${ }^{*}$ E-mail: parisa.ariya@mcgill.ca.

Present Addresses

§F.R.: Department of Chemistry, Shahid Beheshti University, Tehran, Iran.

"E.-A.G.: Centre for Atmospheric Chemistry, School of

Chemistry, University of Wollongong, Wollongong, Australia.

\section{Author Contributions}

All authors contributed meaningfully to the preparation of this manuscript. The final version of the manuscript was reviewed and accepted by all of its authors.

\section{Notes}

The authors declare no competing financial interest.

\section{ACKNOWLEDGMENTS}

We thank H. Khan and Y. Eid for their aid in method development. We also thank P. Carpenter and D. Jacques for allowing us access to the Memorial Pool and Burnside roof for sampling. Funding for this study came from the Natural Science and Engineering Research Funding of Canada, Canadian Foundation for Innovation, Idea-to-Innovation, and Environment Canada. We thank Drs. A. Dastoor and C. Banic for their support. This manuscript benefited significantly from the input of three anonymous reviewers.

\section{REFERENCES}

(1) Morel, M. M.; Kraepiel, A. M. L.; Amyot, M. Annu. Rev. Ecol. Syst. 1998, DOI: 10.1146/annurev.ecolsys.29.1.543.

(2) Amos, H. M.; Jacob, D. J.; Streets, D. G.; Sunderland, E. M.Global Biogeochem. Cycles 2013, DOI: 10.1002/gbc.20040.

(3) Streets,D. G.; Devane, M.K.; Lu,Z.; Bond,T.C.;Sunderland,E. M.; Jacob, D. J. Environ. Sci. Technol. 2011, DOI: 10.1021/es202765m.

(4) Schroeder, W. H.; Munthe, J. Atmos. Environ. 1998 , DOI: 10.1016/S1352-2310(97)00293-8.

(5) Lin, C.-J.; Pehkonen, S. O. Atmos. Environ. 1999, DOI: 10.1016/ S1352-2310(98)00387-2.

(6) Lyman, S. N.; Gustin, M. S.; Prestbo, E. M.; Marsik, F. J. Environ. Sci. Technol. 2007, DOI: 10.1021/es062323m.

(7) Steffen, A.; Douglas, T.; Amyot, M.; Ariya, P.; Aspmo, K.; Berg, T.; Bottenheim, J.; Brooks, S.; Cobbett, F.; Dastoor, A.; Dommergue, A.; Ebinghaus, R.; Ferrari, C.; Gardfeldt, K.; Goodsite, M. E.; Lean, D.; Poulain, A. J.; Scherz, C.; Skov, H.; Sommar, J.; Temme, C. Atmos. Chem. Phys. 2008, DOI: 10.5194/acp-8-1445-2008.

(8) Tong, X.; Barat, R. B.; Poulos, A. T. Rev. Sci. Instrum. 1999 , DOI: 10.1063/1.1150049.

(9) Stratton, W. J.; Lindberg, S. E.; Perry, C. J. Environ. Sci. Technol. 2001, DOI: 10.1021/es001260j.

(10) Landis, M. S.; Stevens, R. K.; Schaedlich, F.; Prestbo, E. M. Environ. Sci. Technol. 2002, DOI: 10.1021/es015887t.

(11) Olson, E. S.; Sharma, R. K.; Pavlish, J. H. Anal. Bioanal. Chem. 2002, DOI: 10.1007/s00216-002-1602-6.

(12) Lyman, S. N.; Gustin, M. S.; Prestbo, E. M. Atmos. Environ. 2010, DOI: 10.1016/j.atmosenv.2009.10.008.

(13) Lyman, S. N.; Jaffe, D. A. Nat. Geosci. 2012, DOI: 10.1038/ ngeo1353.

(14) Huang, J.; Miller, M. B.; Weiss-Penzias, P.; Gustin, M. S. Environ. Sci. Technol. 2013, DOI: 10.1021/es4012349.

(15) Gustin, M. S.; Huang, J.; Miller, M. B.; Peterson, C.; Jaffe, D. A.; Ambrose, J.; Finley, B. D.; Lyman, S. N.; Call, K.; Talbot, R.; Feddersen, D.; Mao, H.; Lindberg, S. E. Environ. Sci. Technol. 2013 , DOI: 10.1021/es3039104.

(16) Lyman, S. N.; Jaffe, D. A.; Gustin, M. S. Atmos. Chem. Phys. 2010, DOI: 10.5194/acp-10-8197-2010. 
https://pubs.acs.org/doi/abs/10.1021/ac504545w

(17) McClure, C. D.; Jaffe, D. A.; Edgerton, E. S. Environ. Sci. Technol. 2014, DOI: 10.1021/es502545k

(18) Engle, M. A.; Tate, M. T.; Krabbenhoft, D. P.; Schauer, J. J.; Kolker, A.; Shanley, J. B.; Bothner, M. H. J. Geophys. Res. D 2010 , DOI: $10.1029 / 2010 J D 014064$.

(19) Risch, M. R.; Gay, D. A.; Fowler, K. K.; Keeler, G. J.; Backus, S. M.; Blanchard, P.; Barres, J. A.; Dvonch, K. T. Environ. Pollut. 2012 , DOI: 10.1016/j.envpol.2011.05.030.

(20) Obrist, D.; Tas, E.; Peleg, M.; Matveev, V.; Faïn, X.; Asaf, D.; Luria, M. Nat. Geosci. 2011, DOI: 10.1038/NGEO1018.

(21) Hynes, A. J.; Donohoue, D. L.; Goodsite, M. E.; Hedgecock, L. M. In Mercury Fate and Transport in the Global Atmosphere; Mason, R., Pirrone, N., Eds.; Springer: New York, NY, USA, 2009. DOI: 10.1007/ 978-0-387-93958-2_14.

(22) Ariya, P. A.; Peterson, K.; Snider, G.; Amyot, M. In Mercury Fate and Transport in the Global Atmosphere; Mason, R., Pirrone, N., Eds.; Springer: New York, NY, USA, 2009. DOI: 10.1007/978-0-387-93958-2_15.

(23) Subir, M.; Ariya, P. A.; Dastoor, A. P. Atmos. Environ. 2011 , DOI: 10.1016/j.atmosenv.2011.04.046.

(24) Harland, P. W.; Thynne, J. C. J. J. Phys. Chem. 1971 , DOI: 10.1021/j100692a005.

(25) Meyer, D. E.; Sikdar, S. K.; Hutson, N. D.; Bhattacharyya, D. Energy Fuels 2007, DOI: 10.1021/ef070120t.

(26) Bombach, G.; Bombach, K.; Klemm, W. Fresenius' J. Anal. Chem. 1994, DOI: 10.1007/BF00326246. 